\title{
Theoretical Design of the Formation of Professional Communicative Competence of Future Non-Language Experts in the Process of Learning a Foreign Language
}

\author{
Oleh Lazariev $^{1}$, Yuliia Fernos ${ }^{1 *}$, Nataliia Komisarenko ${ }^{1}$, Liudmyla Movchan $^{1}$, and Olena Oliinyk ${ }^{1}$ \\ ${ }^{1}$ Uman National University of Horticulture, 1 Instytutska Str., 20305 Uman, Ukraine
}

\begin{abstract}
Competence-based technologies used for teaching a foreign language in non-linguistic higher education institutions, put at the center of all education system student competence, providing comfortable, conflict-free conditions of its development, realization of natural and acquired potentials. The construction of a competence-based educational process presupposes the orientation of the training space on the competence sphere of students. The studied experience makes it possible to identify competencebased "platforms", as well as the main "landmarks" for teaching a foreign language to future experts of non-linguistic specialties. Not only the general English language course, which is quite universal for all specialties, but also the professionally-oriented course, which depends on the chosen specialty in the higher education institution, acquires great importance in the training of future non-language experts. The competence orientation of teaching foreign languages to students of non-linguistic specialties is to ensure proficiency in a foreign language within the framework of both everyday communication and in the specialty at a creative and professional level. Theoretical design of the formation of professional communicative competence of future non-language professionals in the process of learning a foreign language confirms the feasibility of the proposed method, allows us to theoretically justify its effectiveness.
\end{abstract}

\section{Introduction}

The changes taking place in our country and in the world require other approaches to learning a foreign language for students of non-linguistic higher education institutions. Prospects for the development of education are due to both the use of innovative methods and technologies in the meaningfulness of the educational process, and the growth of the teacher's professional competence [1].

The working conditions of foreign language teachers have changed significantly over the last decade. Compulsory for all curricula and textbooks, strict requirements for the organization of the pedagogical process are now a thing of the past; the way is open for choice, initiative and creativity of a teacher. The freedom gained by the teachers imposes many additional obligations: to correctly choose a general learning strategy, specific techniques that correspond to personal characteristics, requests and capabilities of students, the conditions under which training takes place; to select textbooks that are recommended to students as basic and additional, programs and information resources that can be used as a basis, etc.

The development of related sciences, the emergence of psycholinguistics, social psychology, theory of activity gave rise to the development of activity-based competence and communicative technology of teaching a foreign language. The focus is on the formation of communicative competence, taking into account the competencies of students and communicative motivation of the educational process.

This means that communication of ready-made knowledge, cramming, reproduction of other people's thoughts cannot be the leading forms of education nowadays. Consciousness in teaching communication is the ability to navigate the characteristics of the audience, to correlate the tasks, forms and means of your message in a proper way; to predict its influence, possible reactions of the audience or partner.

However, all this is only a general starting point that characterizes the modern approach to teaching a foreign language, its specific implementation depends on the teacher, his psychology, temperament, language skills and similar characteristics of his students. The teacher himself has the right to decide whether his students need an oral introductory course, what type of motivation he can rely on in the first place - communicative, cognitive, aesthetic or game[2].

Achieving the main goal of teaching foreign languages to students is possible, in our opinion, only in terms of communication. Thus, communication is a means to an end, a means of learning. The educational task is the formation of students' competencies, which means the possession of a number of skills and abilities that allow them to communicate in everyday and professional spheres. Education of the future expert is considered by us as education of the man of culture and highly qualified expert (in this case by means of a foreign language), capable to solve work problems and 
to create proper cultural environment around himself/herself.

If the teacher communicates easily and attracts others to communication, then it is advisable to focus on the development of oral speech by means of dramatization, role-plays, etc. The implementation of this task expands the horizons of students in the field of literature, history, general scientific knowledge, increases their general culture, as well as the culture of thinking, communication, language.

In accordance with these subsystems, it is possible to determine interrelated landmarks that can form the basis of teaching a foreign language in non-linguistic higher education institution in the context of competence-based education.

\section{Literature review}

Studying the issues of teaching a foreign language, one should focus more on the student's independent creative activity, on the search for the optimal strategy for mastering the language, on the use of his own hidden reserves and potentials. New methods of teaching a foreign language, developed in the $90 \mathrm{~s}$, are aimed at this training, which reveals the possibilities of the future expert. There are a number of psychological theories and concepts that are directly related to the process of mastering a foreign language, in particular the theory of gradual assimilation of knowledge and formation of scientific concepts (P. Halperin); psychological theory of collective-distributive educational activity (V. Rubtsov, H. Zuckerman, etc.); psychological theory of formation of educational activity (D. Elkonin, V. Davydov); psycholinguistics in domestic modification (A. Leontiev, A. Zalevskaya, etc.). All these theories and concepts, which eventually developed into the approach first described by the genius psychologist L. Vygotsky, not only do not contradict each other, but can and should lead to the development of new aspects of methods of teaching foreign languages [3]. For example, problem-based learning (PBL) is becoming more and more relevant. This is done by setting problematic tasks (find, learn, understand, express an opinion, argue, oppose, etc.), search and orientate in ways to solve them so that the student can come to an independent conclusion and, on this basis, to activity. Management of educational activities is implemented in the direction from receptive to productive skills. However, some scholars argue that "The sense-making process that PBL is supposed to be then becomes nonsense when the group is not able to recognise and correct misinterpretations. In situations like this we need critical questions, but students seldom ask critical questions" [4].

In the context of a student-centered approach to teaching foreign languages in foreign theory and practice of teaching, the concept of learner autonomy and autonomous self-directed learning was proposed by H. Holec [5]. Its main provisions are as follows. The autonomy of a student in the process of mastering a subject is understood as "the ability to take responsibility for one's educational activity" is defined by H. Holec through the concept of "educational competence". This concept is a personal characteristic and can be considered as a broad student's ability to make decisions, reflection, analysis of the learning situation and his experience, awareness of himself as a subject of learning activity, responsible for its result.

The most adequately productive skills are realized, as a rule, only in interpersonal communication. "By the nature of solving educational problems management should be implemented according to the principle - from receptive to productive, in reception - from visual to auditory modality, from emotionally neutral to emotionally charged, from personality-oriented to socially-oriented, from socially symmetrical to socially asymmetric" [6].

Researcher M. Kabardov believes that according to their individual characteristics, those who study foreign languages are of two types: "communicative type" with developed auditory memory, once in a foreign language environment, they quickly hear the basic stereotypes of language communication. Students of the so-called "non-communicative type" must understand the language system, they have a predominant visual memory, they need to see a foreign text, so it is easier for them to understand its content than to perceive it by ear [7].

The experience of teaching foreign languages in higher education establishments allows us to draw conclusions about the great potential and feasibility of using role-based communication in teaching. Role theory has been used in research related to the use of roleplaying games in foreign language teaching [8-10].

\section{Results of the study}

The use of competence-based technologies will contribute to solving the problem of intensifying the process of teaching a foreign language to students of non-linguistic higher education establishments. Technology can become competence-oriented under two conditions: the availability of competence content emanating from students and teachers, as well as stepby-step implementation. The concept of competencebased education is an attempt to combine humanitarianism and technocraticism. Competencebased technologies used in teaching a foreign language in non-linguistic education establishments, put in the center of the entire education system the competence of the student, ensuring comfortable, conflict-free conditions for its development, and realizing natural potentials. Student's competence in this technology is a priority of the object, the goal of the education system, and not a means to achieve any abstract goal. Competence-based technologies are aimed at diverse, free and creative development of the student. They are more flexible and varied, related to specific problems and situations of individual, personal development of the subjects of the educational process: students and teachers. A teacher needs to organically combine two systems: teaching the subject and working with students. 
Nowadays, it is a completely natural process of mastering new technologies, in which traditional methods, and developmental learning, as well as competence-based elements of teaching can be used. In this combination, the teacher of a foreign language of non-linguistic education establishment gets an opportunity for personal orientation of various stages of educational activity in the use of proven methods (including personality-oriented, consciously-practical, problem-solving, communicative, intensive learning and game modeling).

The construction of a competence-based educational process involves the orientation of the learning space on the competence sphere of students. Training is based on dialogues of various levels: formal dialogue - dialogue as a form of communication between participants in the educational process; meaningful dialogue - presentation in a dialogical form and content of educational activities; semantic dialogue - dialogue as a way to establish valueoriented unity.

In the conditions of competence-based teaching of a foreign language, each student of the group is actively involved in the communication process, gets a real opportunity to meet socially important needs in achieving prestige, status, attention and respect from others. The teacher creates a tone of communication saturated with joy, benevolence, satisfaction with the success achieved and confidence in the final result of training.

Having studied the previous experience, we will consider the features of competence-based "platforms" for teaching a foreign language to future experts of nonlinguistic specialties.

Modular platform. A separate module of the studied educational material is necessarily accompanied by rating control of students' knowledge and skills. The basis for the formation of modules is the curriculum of the discipline, consistent with the government educational program. Control of modules includes: modular control, tests or exams.

Expansion platform. Teaching with increased didactic units provides a general vision of the topic, a holistic perception of the material. Several lessons on one common theme are united by a cross-cutting plot.

Communication platform. The main participants in the process are the teacher and the student. The relationship between them is based on cooperation and equal language partnership.

Semantic platform. The main thing is to create emotional and psychological attitudes, the ability to influence the feelings of students, building the drama of the lesson.

Interaction platform. The work is organized in pairs of variable composition.

Problem platform. The teacher creates a problem situation and students solve it independently, as a result of which there is a creative mastery of professional knowledge, skills, abilities and the development of thinking abilities.

Business game platform. Students imitate reality. This helps fit the educational process in the context of their real life as future experts. Students act out situations aimed at recreating and assimilating social and professional experience, in which self-management of behavior develops and improves.

Intensive learning platform. Techniques are used that activate the conscious and subconscious processes of the psyche to create a large and strong language base. Tasks that motivate communication are developed. The use of this technology involves an increase in the number of hours.

Advance platform. Advanced knowledge and tasks, such as those that precede the perception of a foreign language or reading a text in a foreign language, contribute to the effective preparation of students to learn new material.

Information and technical platform. Use of computer, Internet, video, audio, multimedia, interactive means, etc. One of the organizational foundations is the digitalization of education, the use of information technology and software for learning a foreign language.

Remote platform. In response to the challenges of global circumstances that dictate the organization of distance and blended learning, effective forms of learning foreign languages are being developed in conditions of forced and planned extracurricular learning.

The principles of the competence-based approach and the orientation of learning to the development of a student's secondary linguistic personality are correlated with the subsystem "learning objective". The following principles are correlated with the subsystem "learning content": situationality, modeling, dual function of educational communication. The principles of homogeneous formation of subgroups, the activity basis of learning, and group influence determine the learning process. The principle of orientation towards a profession/specialty corresponds to the subsystem "learning outcome" [11].

According to the proposed principles, we will consider the main landmarks for teaching a foreign language to future non-language experts.

Personal landmark. The teacher and the student are like-minded people. Human communication begins with establishing contact. Initial communicative adaptation and readjustment of those who communicate are needed. In such conditions, complexes, internal tension are removed, confidence and mutual understanding come.

Direction landmark. Learning a foreign language is aimed at developing the features of the secondary language personality, that is, the teacher not only teaches the student to behave with the help of a foreign language as a native speaker, but also develops his willingness to carry out textual activities in the language studied, the ability to adequately interact with other cultures.

Situational landmark. When learning a foreign language, it is important to select and organize material based on situations and communication problems that interest each student. Motivation to speak arises only in the reproduced situation, as a result of which they speak.

Modeling landmark. The amount of knowledge of the country is very large, threfore, it is necessary to select a sufficient amount of material to present the culture of 
the country in a concentrated form. In this case, the content of the language consists of problems, not topics. In order to minimize and streamline linguistic knowledge, the language system is given in a model form: schemes, tables, comparisons, etc.

Double landmark. The dual function of educational communication is that this communication is planned for the teacher. The teacher guides the communication in order to form, practice and consolidate the skills and abilities of all types of speech activity. For students, communication is a goal, since with the help of language they can go beyond educational situations.

Differentiation landmark. Students take placement test, which determines the level of their knowledge of a foreign language. According to this level, educational subgroups are formed.

Activity landmark. The activity basis of learning is expressed in the external and internal (mental) activity of the student, passive and active stock of knowledge. The volume of independent, group and collective forms of learning is increasing, while the traditional frontal work, in which language activity is shown by the teacher, and students are active only if they are asked, is being reduced.

Group landmark. The individuality of each student is revealed through communication. Interpersonal interactions can be considered in three directions: communication between teacher and student, communication between teacher and the whole group, communication between students. The educational subgroup should have a psychological microclimate that allows you to effectively identify and reveal the capabilities of each student.

Professional landmark. This orientation is based on profession and specialty. The curriculum of teaching a foreign language to students of non-linguistic specialties focuses on learning the basics of business communication and the language of the specialty. In higher education institutions, students are gradually immersed in the language and essence of the profession or specialty. They learn to communicate in a foreign language and read literature on their future specialty, deal with business documents, annotate scientific texts, etc.

In the methodology of teaching foreign languages, the importance of a role is considered in the structure of educational and speech situations, where it is determined by the fact that the role can contain information in the estimated volume of a language product, the sphere of oral communication, language material necessary to formulate an utterance, the subject content of a message and other characteristics of the speech act. The role is considered as an important component of the learningspeaking situation, which focuses on its basic parameters and the corresponding concept of conversational practice. Game conditions are always correlated with real conditions, this makes it easier to find patterns of behavior and means of verbalizing statements. In these conditions, the information that the student receives from communication partners is also involved in the individual cognitive process. B. Lomov believes that "this, first of all, determines the higher efficiency and originality of the dynamics of cognitive processes in communication" [12]. As a result, the student's attitude to the subject, which appears to him not only as an object of knowledge, but also as a means of satisfying needs in certain relationships with group members, changes. In other words, the effect of solidarity, which in fact characterizes any collective activity, becomes a personal motivation for everyone's activity.

Role-playing at a later stage of learning can be combined with a business game. Business games are a type of learning, in which the acquisition of knowledge, the formation of skills and abilities are superimposed on the canvas of professional activity, in training it is presented in a certain model form. Makoviei O. M. states that "the advantage of business games lies in combining both theory and practice, contributing to the formation of professional knowledge and practical skills. Games increase the interest in the subject being studied, as they are accompanied by positive emotions." [13].

However, transferring business games to the field of teaching foreign languages, one should realize that business games must be a logical and natural continuation of role-playing games in conditions when students are linguistically and professionally ready to implement foreign language professional activity. Thus, business games should be introduced in the last years of non-linguistic higher education institutions, if the previous stage of training was conducted in the form of role-playing games, which are necessary in the business game, when students' attention is focused on the professional aspect. In this case, it will be justified by the fact that in the last stages of study, students already have an idea of their future professional activity and must prepare for it. It is role-playing games that teach the norms of verbal communication, provide mastery of those communicative units that are necessary for participation in a business game, when students' attention is focused on the professional side of verbal behavior and language activities.

Describing the competence-based organization of foreign language teaching of future non-language experts, we must not forget that it characterizes only one side of a complex dialectical unity, consisting of the interaction of organized in a certain way educational material and the process of teaching itself. Thus, the adequacy of the organization of educational material for the learning process becomes of paramount importance. The organic unity of the subject and the process in teaching a foreign language was first proposed by $\mathrm{G}$. Lozanov, who claims that the main educational text is a polylogue, and the participants in this polylogue are the students

themselves [14]. According to the story line of the whole course, each student gets a "new role" wearing a "new mask" with its responsibilities, based on which a proper demeanor is chosen. A student must rebuild relationships with all unfamiliar members of the group within the norms and rules that are set in the new organization, i.e. in the group of tourists, or in the group of experts who came to the congress, or in a group of students from any country who came to study in this higher education establishment, etc. In the practice of such training there 
is no conflict between "student-mask" and "studentstudent", because the educational texts contain, at least symbolically, positions, values and personal attitudes of actors, which do not contradict the worldview of students and contributes to disclosure of positive qualities, in particular, creative imagination, etc.

The significance of the introduction of the legendmask according to A. Leontiev [2], is that it allows the student to "express himself/herself", which generates a psychotherapeutic, psycho-hygienic effect, as it frees students from "clamps", from fear of mistakes, feelings of shame and inconvenience. Psychological barriers are removed, students' creative opportunities are opened and activated. Changing the names and distribution of legends in the group is to some extent a methodological technique, since the phonemic and lexical-grammatical organization of the "autobiography" of the group members allows to put phonemes in semantic opposition, and the development of "legends" in vital situations partially compensates for the lack of an introductory phonetic course. Situations of educational dialogues are selected in such a way as to simulate the speech behavior of each, unite the group with a single activity of verbal communication. This joint language activity, "embedded" in the textbook, forms a team and creates a favorable psychological climate for joint activities [15].

For example, one of the variants of modern technology of teaching students of humanitarian universities, proposed by L. Shestoperova: "Learning is a system of generalized structured knowledge, based on clearly constructed functional modules, as well as differentiated rules of formation and operation of grammatical phenomena for reading and translating special popular science and special literature" [16]. In the training of future non-language experts, not only the general English course, which is quite universal for all specialties, but also a professionally oriented course, which depends on the chosen specialty of the higher education institution, is of great importance. Business English is predominantly taught in the Master's program.

In addition, due to the lack of hours of teaching a foreign language, it is being intensified - the types of work with text are expanding, the number of creative exercises is increasing in comparison with lexical and grammatical ones. Creative opportunities are manifested not only in the course of ordinary text-based training sessions, but also in the preparation of messages, in the expansion of topics, more complex vocabulary is mastered. The nature of the dialogues is also changing professional topics are discussed: the economic and professional components of labor, the conclusion of contracts, the criteria and principles for hiring, the types of activities of the organization, management, and the like. Such a topic not only significantly expands the language capabilities of students in a professional sense, but also contributes to the growth of future experts' confidence in their capabilities, the formation of professional communicative competence, an increase in interest and motivation in learning a foreign language, for its more in-depth assimilation [17].

In parallel, work should continue on reading periodicals or books in a foreign language in the specialty, watching films, news, social networks, Internet resources. At this stage, the student's task is not only to reveal the content, but also to analyze what has been read. The learning process includes group discussions, comparison with their own knowledge, identification of ambiguities. Practical classes are held in the form of round tables, debates, seminars where certain professional problems are discussed, and the like. The topic and nature of such conferences is determined both by the teacher and offered by the students of the educational subgroup. For example, "Farming in Ukraine and GB", "Agroecology", "Students' scientific researche", "Future career", "Job hunting" and others. If the subgroup is already accustomed to this type of activity, then it not only enthusiastically takes part, but also prepares for this type of activity, especially willingly selecting and deeply studying a large amount of material on the selected topic. It is precisely such a diverse multilateral educational activity that not only helps to study and master a foreign language, but also stimulates research work, independence, develops creative thinking, professional communicative competence [18].

However, if the main task was to provide the student with language training for a short trip abroad in the shortest possible time, it would be advisable to use G. Lozanov's method [14] or methods that go back to it, developed, for example, by G. Kitaygorodskaya and I. Shekhter $[19,20]$. Practice shows that in a couple of weeks of intensive classes using this technique, English can be mastered at a level sufficient for effective communication in various life situations - at the airport, hotel, shop, on the street, etc. But if a student does not go to an English-speaking country in the near future and does not have intensive language practice, after a maximum of six months, everything learned will become passive vocabulary. A separate approach is required for effective preparation for the single entrance exam students take to get their master degree in Ukraine, where the tasks textually do not meet either the curriculum requirements or areas focused on the specialty. And what ultimately turns such an exam into a "dropout tool" is the unjustified time limit of up to one hour for all exam tasks. If English is required for professional purposes, and the student intends to travel, for example, to the United States for a long time, in this case it requires a different teaching method that allows you to gain a basic knowledge of the language, as well as in-depth and expanded knowledge of it. Thus, not all foreign language courses are professionally oriented in terms of methodology.

The distribution of educational material over time should take into account not only the methodological conditions and requirements, but also the attitude of students towards it. In the context of the competencebased orientation of teaching foreign languages, it is necessary to take into account the interest of students in one or another topic, the desire to develop it or move on to another. It should be noted that the focus on students' interest in the distribution of educational material contributes to the strengthening of trust between the 
teacher and students and increases the responsibility of students for the results of work.

Under this approach to learning, students develop their skills related to intellectual and mental processes: to receive, analyze, compare, develop, systematize information focused on a specific educational goal; to express one's own opinion from what has been read or listened to, to generalize information; make a plan, formulate abstracts, compile a summary; prepare reports, presentations, essays or short messages; search for and extract the most important information, according to a certain educational task.

Theoretically, after completing such a competencebased course, students should be able to: conduct a conversation in the conditions of everyday, professional and business communication - at meetings with foreign colleagues during negotiations, when concluding agreements and signing contracts, at seminars, webinars, workshops, round tables, conferences, symposia, congresses, etc.; have the skills to speak on different topics and in different situations - a story, a short information, clarifications, explanations, a report, a consultation; process business correspondence - draw up business letters, send and receive information through modern means of communication; read, translate and understand the main content of original professional texts, extract necessary, important and useful information.

In this study, the positive role of languages is that they can be used outside the national framework of their functioning as: one of the means of expanding access to information, its dissemination regardless of national borders; a means of understanding and studying the diversity of cultures and civilizations, ways and results of their interactions in the world flow of culture; means of interethnic and intercultural cooperation and cooperation in science and social activities of people, contribute to the search for common ways to solve common problems, ways out of conflicts arising in human relations, society and nature; a means of overcoming national and cultural limitations in various spheres of society; a means of preserving, disseminating and developing world culture; one of the means of removing the linguistic barrier in ensuring the human right to free movement in the world, choosing a place to study and work, leisure, participation in various international organizations. But the most important function of language is to serve as a tool for the development of global thinking and a means of teaching intercultural communication.

In turn, the professional portrait of an expert consists of a set of professional, competence, socio-psychological and personal qualities. In an integrated form, these qualities can be identified, written off and interpreted as professional communicative competencies: the ability to interact, to integrate with experts in related and other specialties; ability to manage the workforce; ability to organize people; follow the ethical and legal norms of society; presence of axiological formations - ideals, values, priorities, motivations, principles, ambitions; knowledge of ways to resolve conflicts, the ability to conduct business negotiations; knowledge of cultural, national, socio-psychological characteristics of the behavior of people of a region, country; mastery of communication techniques, language skills, forms of language communication. The effectiveness of the process of formation of professional communicative competencies depends on a number of conditions: the organization of foreign language learning in the context of future professional activity - vocational training; application of a system of measures to increase motivation, development of students' need for professional communicative competencies; development of the mechanism of pedagogical support; development of educational and methodical support. All of the above creates the basis for the formation of professional communicative competence of future non-language professionals.

\section{Conclusion}

Thus, the theoretical design of the formation of professional communicative competence of future nonlanguage experts in the process of learning a foreign language confirms the feasibility of the proposed method, theoretically justifies its effectiveness, including measures to increase students' motivation to master professional communicative competence, a set of techniques and tools for the formation of skills and abilities of verbal communication, organization of the learning environment.

In order to teach a foreign language using a professional method, it must, first of all, meet several interdependent points: adequacy of learning goals and conditions; ensuring the acquisition of all aspects of language (and not only learning vocabulary and consideration of grammatical phenomena); the possibility and availability of technology to monitor the effectiveness of training.

Drawing on the pedagogical experience of teaching a foreign language to students of non-linguistic specialties on the basis of a competence approach, it is necessary to begin the educational process in the first year to determine the personal interests of students and their prior language training. Based on these data, you can form subgroups and select a curriculum. Experience of teaching in non-linguistic higher education institutions, interviews with students and questionnaires showed that students working under CBL realize the importance of a foreign language in becoming a professional. Basically, such a program is aimed at modeling learning, which stimulates the development of competencies of students who act as subjects of the educational process in a foreign language.

Thus, the competence-based approach of teaching foreign languages to students of non-linguistic specialties is to ensure knowledge of a foreign language in the framework of both everyday communication and specialization at the creative and professional level. The integrity of the learning process depends on the interconnection of all its components. The target setting for the development of a competent expert strengthens 
the emphasis on educational tasks with a focus on dialogues about world and domestic cultural values

Mastering a foreign language without getting acquainted with the culture of the country, the mentality of people who speak this language can not be complete. In other words, it is necessary to master not only the language itself, but also the worldview of those who speak it. This does not mean that one should think and act like the people of the country whose language is being studied. But you should put yourself in the place of an English-speaking interlocutor to know and understand at least a minimum of what surrounds him in everyday, social and professional life.

So, the process of mastering a foreign language becomes economical and effective if the student understands why and how he learns, and realizes the communicative value of each language unit that he masters. It is also important to establish a link between practical and developmental goals. Here, the developmental goal is considered not as an expansion of horizons (educational aspect), but as the development of intelligence, respectively, the development of intellectual operations, which underlie the functioning of language skills and abilities.

Thus, the above allows us to assert that the competence-based organization of educational material provides a clear relationship between the academic discipline and the educational process, contributes to the effective implementation of the goals of teaching a foreign language and the formation of professional communicative competence of future non-language experts. One of the main provisions of the competencebased approach to teaching a foreign language is the focus on developing the competence of the student as an active subject of educational activity and comprehensive preparation for the continuous process of education, selfdevelopment and self-improvement throughout life.

\section{References}

1. A. Dubskikh, N. Zerkina, in Current trends in the development of education system, ed. by $\mathrm{Zh}$. Murzina, G. Nikolaieva, N. Tolstov (Cheboksary, 2018), p. 108. doi: $10.31483 / \mathrm{a}-28$

2. A. Leontiev, FL at school. 2, 27-32 (1986)

3. L. Vygotsky, in The collected works of L.S. Vygotsky, ed. by R.W. Rieber \& A.S. Carton. Thinking and speech, vol. 1 (New York, Plenum Press., 1987), pp. 39-285

4. $\quad$ Dirk Humalda, Research in HM. Volume 6 (2), 207212 (2016). doi: 10.1080/22243534.2016.1253292

5. H. Holec, Autonomy and Foreign Language Learning, 2nd edn. (Pergamon, Oxford, 1979).

6. I. Zimniaia, Psychology of teaching a non-native language. (Moscow, 1989), p.97

7. M. Kabardov, Ye. Artsishevskaia, Psych. issues. 1, 34-49 (1996)

8. A. Kotkovets, Journal of the National Technical University of Ukraine "KPI": Philol. and Educ. Studies. 7, 43-49 (2016)
9. Rafsanjani Ali Akbar, Andhika Ratna, Budiana Haris, VEL, Vol 1, No 1, (2020). Available at http://jurnal.unswagati.ac.id/index.php/ELTERA/arti cle/view/2340

10. O. Honcharova, A. Krasulia, in Innovations and traditions in language training of students. Proceedings of the international scientific-practical seminar, Kharkiv, 6 December 2019, pp.91-93

11. I. Stasiukevich. Dissertation, Stavropol State University, 2005. p. 109

12. B. Lomov, Psych. journal. Vol.1, 1, 23-45 (1980)

13. O. Makoviei, Automobile Transport. Vol. 43, p.119 (2018). doi: 10.30977/AT.2219-8342.2018.43.0.118

14. G. Lozanov, Dissertation, RUDN University, 1970

15. G. Kitaigorodskaia, Activating learning activities. (Moscow, 1982)

16. L. Shestoperova, A practical course on the main sections of English grammar. (Moscow, 1995)

17. O. Lazariev et al, in Vision 2025: Education Excellence and Management Innovations through Sustainable Economic Competitive Advantage, ed. by Khalid S. Soliman. Proceedings of the 34-th IBIMA Conf. 13-14 Nov. 2019. (Madrid, Spain, 2019), pp. 11099-11107

18. O. Lazariev, Yu. Fernos, Pedagogy of creative personality formation in higher and general education schools. Issue 73, vol 2, 77-81 (2020). doi: 10.32840/1992-5786.2020.73-2.14

19. G. Kitaygorodskaya, Methodology for intensive teaching of foreign languages (Moscow, 1986)

20. I. Shehter, in Methods and psychology of intensive learning (Moscow, 1981) 